\section{Estudo morfo-anotômico entre os caules de Lippia alba e Melissa officinalis}

Ferreira, J.L.P. ${ }^{1,2,3}$, Velasco, E. ${ }^{1}$, Araújo, R.B.de ${ }^{1}$, Kuster, R.M. ${ }^{2}$, Amaral, A.C.F. ${ }^{1}$

${ }^{1}$ Laboratório de Química de Produtos Naturais, FarManguinhos, Fiocruz, Rio de Janeiro (RJ) Brasil;

${ }^{2}$ Núcleo de Pesquisas de Produtos Naturais, Universidade Federal do Rio de Janeiro, Rio de Janeiro (RJ) Brasil; ${ }^{3}$ Laboratório de Farmacognosia, Depto. de Farmácia e Administração Farmacêutica, Faculdade de Farmácia, Universidade Federal Fluminense, Niterói (RJ) Brasil.

\section{Resumo}

São analisadas as características microscópicas entre os caules de Lippia alba e de Melissa officinalis, ambas conhecidas no Brasil como "ervas cidreiras" e consumidas pela população em virtude de suas propriedades sedativas e antiespasmódicas. A análise dos cortes transversais dos seus caules, que geralmente aparecem misturados às folhas das duas espécies em estudo, auxilia a diagnose da matéria prima vegetal.

\begin{abstract}
The microscopic characteristics of the stems of Lippia alba and Melissa officinalis, both known in Brazil as "erva cidreira" and consumed by the population in virtue of their sedative and antispasmodic properties, were analyzed. Analysis of the transverse section these stems, which often appear mixed with the leaves of the two species, help in the differentiation of the raw plant material.
\end{abstract}

O emprego das folhas de Lippia alba (Miller) N. E. Br. ex Britt. \& Wilson (Verbenaceae) em substituição às de Melissa officinalis L. (Lamiaceae) é bastante difundido no Brasil para o tratamento de distúrbios digestivos e respiratórios. Embora ambas as espécies sejam conhecidas popularmente como "ervas cidreiras", somente a segunda é considerada oficinal ${ }^{1,2}$. As características microscópicas entre suas folhas são descritas na literatura e servem para diferencia-las em produtos fitoterápicos que às contêm ${ }^{2,3,4,5,6}$. Não obstante é comum aparecerem misturados às folhas diversos fragmentos de caules, geralmente com o objetivo de aumentar o peso final da matéria prima comercializada.
O intuito do presente trabalho é analisar anatomicamente estes caules com a finalidade de contribuir com mais subsídios que permitam o controle da qualidade farmacognóstico de produtos comerciais que os possuam, mesmo quando pulverizados.

O caule jovem de Lippia alba (Fig. 1-A), de contorno quadrangular, apresenta em secção transversal uma epiderme uniestratificada, de cutícula estriada e pubescente, com células de forma aproximadamente poligonal. Os tricomas tectores são quase sempre unicelulares (raramente pluricelulares), na maioria das vezes longos, agudos no ápice e de paredes espessadas. Os curtos, uni ou bicelulares, são muito pouco frequentes (Fig. 3-I). Os tricomas glandulares são sésseis ou de pedicelo muito pequeno, suportando cabeça glandulosa uni ou pluricelular, neste último caso geralmente bicelular, raramente apresentando 4 células (Fig. 3-J). O colênquima é do tipo angular, com 3 a 6 estratos de células de tamanhos e formas variáveis. O parênquima cortical mostra 2 a 4 camadas de células isodiamétricas, onde podem ser visualizados grãos de amido isolados ou agrupados e cristais de oxalato de cálcio em forma de prismas. A região vascular apresenta feixes bicolaterais com um floema externo de maior desenvolvimento, possuindo todos os seus elementos (tubos crivosos, células companheiras e parênquima). O floema interno, pouco desenvolvido, encontra-se distribuído em pequenos grupos. O xilema aparece em vários conjuntos dispostos radialmente, separados por largas faixas de parênquima, cada feixe sendo constituído geralmente por 1 a 4 elementos bem nítidos. Observase a presença de um câmbio fascicular entre o floema e o xilema de cada feixe e o início de um câmbio interfascicular. Ao centro nota-se um parênquima medular desenvolvido, de células poligonais grandes contendo grãos de amido isolados ou agrupados e raros cristais prismáticos de oxalato de cálcio. O caule adulto de contorno aproximadamente circular, em estrutura secundária, mostra um súber pouco desenvolvido; parênquima cortical com células de formato e dimensões variáveis contendo grupos de células pétreas, grãos de amido isolados ou agrupados e grandes maciços de fibras de paredes muito espessas e lignificadas (Fig. 1-B). Podem ser observados um floema externo (mais desenvolvido) e outro interno (bem discreto), com células crivosas, companheiras e parênquima. O câmbio vascular com 2 a 3 estratos de células tabulares delimita externamente o xilema, o qual contém vasos de paredes com perfuração areolada, dispostos em fileiras radiais que estão separadas por longas faixas de fibras e parênquima (Figs. 1-Ce D). A região central é ocupada por parênquima rico em grãos de amido (Fig. 1-D). 

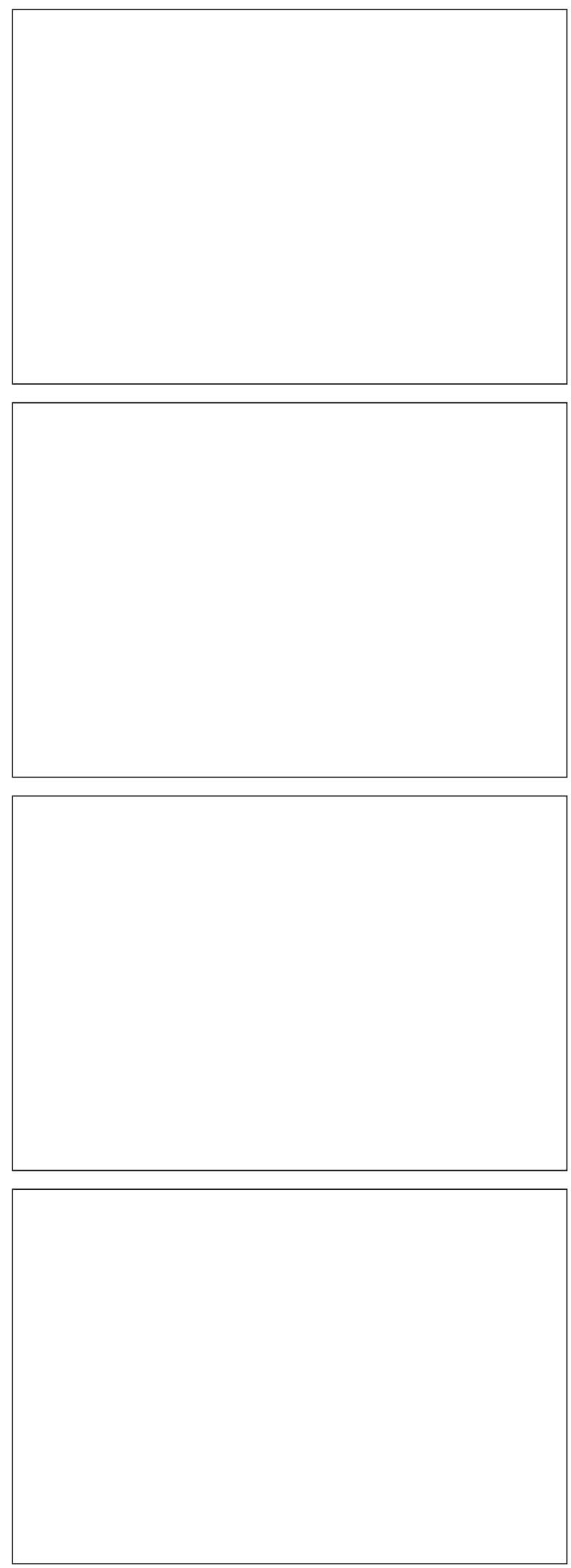

O caule jovem de Melissa officinalis (Figs. 2E e F), de contorno quadrangular, em secção transversal apresenta epiderme uniestratificada com células de contorno poligonal e cutícula estriada. Observa-se com frequiência tricomas tectores curtos, cônicos, unicelulares, de paredes espessas e superfície finamente granulosa. Ocasionalmente podem aparecer tricomas longos, pluricelulares, com 3, 4 ou 5 células, caducos (Fig. 4K). Os tricomas glandulares são geralmente sésseis ou de pedicelo curto, suportando cabeças glandulosas uni, bi, ou octocelulares, envolvidas por uma cutícula comum (Fig. 4-L). O colênquima é do tipo angular, com maior espessamento nos ângulos do caule. O parênquima cortical é representado por células arredondadas de tamanhos variáveis, com cerca de 4 a 5 estratos celulares, as quais podem apresentar inclusões de amido e nas proximidades do feixe vascular, uma autêntica bainha amilífera. O floema externo possui células crivosas, companheiras e parênquima, enquanto no interno estes elementos se dispõem em pequenos maciços separados por células de parênquima. O câmbio fascicular, primário, é observado apenas junto ao floema externo, representado por 2 a 3 camadas de células. $\mathrm{O}$ xilema nos feixes maiores possui várias séries de 2 a 8 elementos vasculares de meta e protoxilema arrumados em fileiras radiais, entre os quais está situado o parênquima radial onde nota-se um esboço de câmbio interfascicular ao nível do câmbio anterior. A região medular, muito desenvolvida, está formada de células parenquimáticas, poligonais, de paredes finas, podendo conter grãos de amido, porém sem a presença de cristais. $O$ caule adulto, de contorno quadrangular, apresenta um súber de células tabulares ou pode possuir em seu lugar uma epiderme uniestratificada de células poligonais, revestida por uma cutícula espessa e estriada. O colênquima angular é bastante desenvolvido nos ângulos do caule, sendo seguido por um parênquima cortical que mostra às vezes pequenos espaços intercelulares. A região vascular é delimitada externamente por uma camada descontínua de fibras que protege o floema externo, muito desenvolvido. O floema interno encontra-se em pequenos núcleos discretos, separados por células parênquimáticas. A região cambial pode ser descontínua em alguns trechos (Fig. 2-G). Os vasos xilemáticos estão distribuídos em fileiras radiais, separadas por fibras e parênquima. A medula, de células isodiamétricas, com paredes espessas, podem conter grãos de amido (Fig. 2-H). 

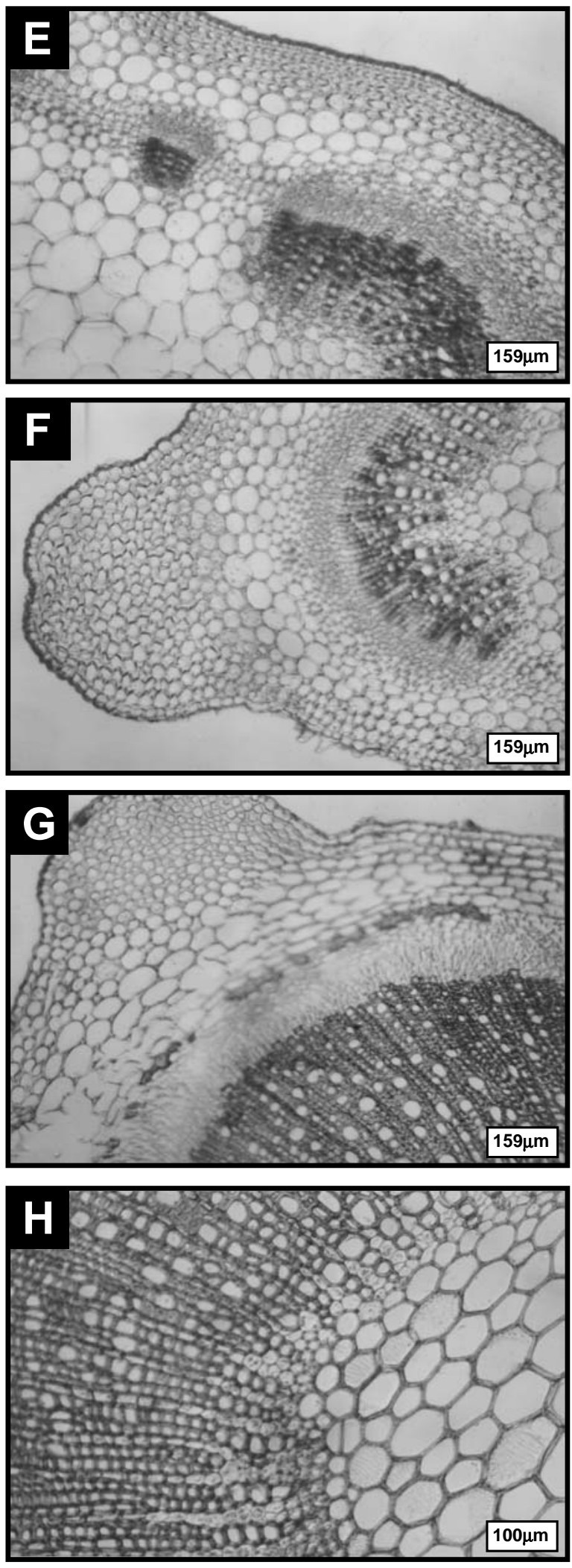

Figura 2. Fotomicrografias de secções transversais do caule de Melissa officinalis (E - H). E - Visão geral do caule jovem; F-Saliência do caule jovem com tricomas; G - Córtex e início da região vascular do caule adulto; H - Final da região vascular do caule adulto com xilema radial e parênquima medular.
Deve-se destacar na secção transversal da região mediana dos caules jovens das duas ervas cidreiras a presença de epidermes uniestratificadas, com células de contorno poligonal, revestidas por uma cutícula estriada. Tricomas tectores unicelulares, longos, de paredes espessas são observados em L. alba enquanto que em M. officinalis eles são geralmente curtos, cônicos, unicelulares. Os tricomas glandulares do caule de $L$. alba mostram-se sésseis ou de pedicelo curto, suportando uma cabeça glandulosa unicelular ou bicelular, raramente com quatro células. Em M. officinalis estes tricomas também estão presentes, com destaque para o pluricelular, característico da família Lamiaceae e auxilia a diagnose mesmo quando o produto encontra-se pulverizado. $\mathrm{O}$ colênquima angular e o parênquima cortical são semelhantes para as duas ervas cidreiras. Este segundo tecido, com grãos de amido isolados ou agrupados em $L$.alba, possui uma verdadeira bainha amilífera nas proximidades do feixe vascular em $M$. officinalis. A região vascular das duas espécies estudadas apresenta floema externo mais desenvolvido, com todos os seus elementos e outro interno, mais discreto, representado por pequenos grupos de células. O xilema encontra-se disposto em fileiras radiais de vasos que estão separados por raios parenquimáticos. $\mathrm{O}$ câmbio fascicular é evidente entre o floema e o xilema de cada feixe e nota-se a formação discreta do câmbio interfascicular. São observados vários feixes vasculares de dimensões variadas, dispostos em círculo. A região medular é bastante desenvolvida no caule das duas cidreiras e contém os mesmos elementos descritos para o parênquima cortical. Em alguns produtos comerciais é possível encontrarem-se fragmentos de caules adultos, com o crescimento secundário já iniciado. Neste caso, embora a epiderme possa continuar evidente (muito comum em M. officinalis), normalmente ocorre sua substituição pela periderme. No parênquima cortical são visualizadas células esclerosas, isoladas ou em grupos em L. alba, aparecendo entretanto em M. officinalis na forma de um anel descontínuo na região interna. Maciços de fibras, volumosos, são observados em $L$. alba. A região vascular, muito desenvolvida, possui feixes em crescimento secundário, separados por câmbio vascular nítido. Estes resultados auxiliam na diagnose botânica destas matérias primas vegetais e podem ser importantes quando as folhas no produto final se encontrarem muito fragmentadas, dificultando a análise. 

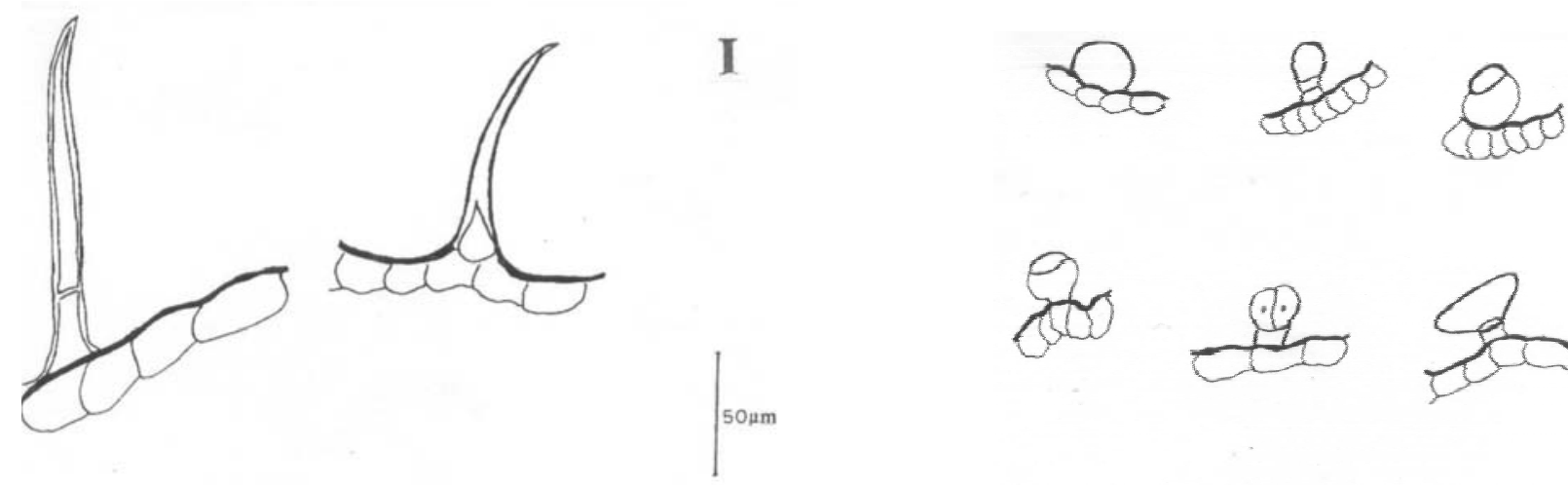

$\mathbf{J}$

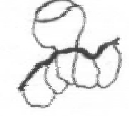
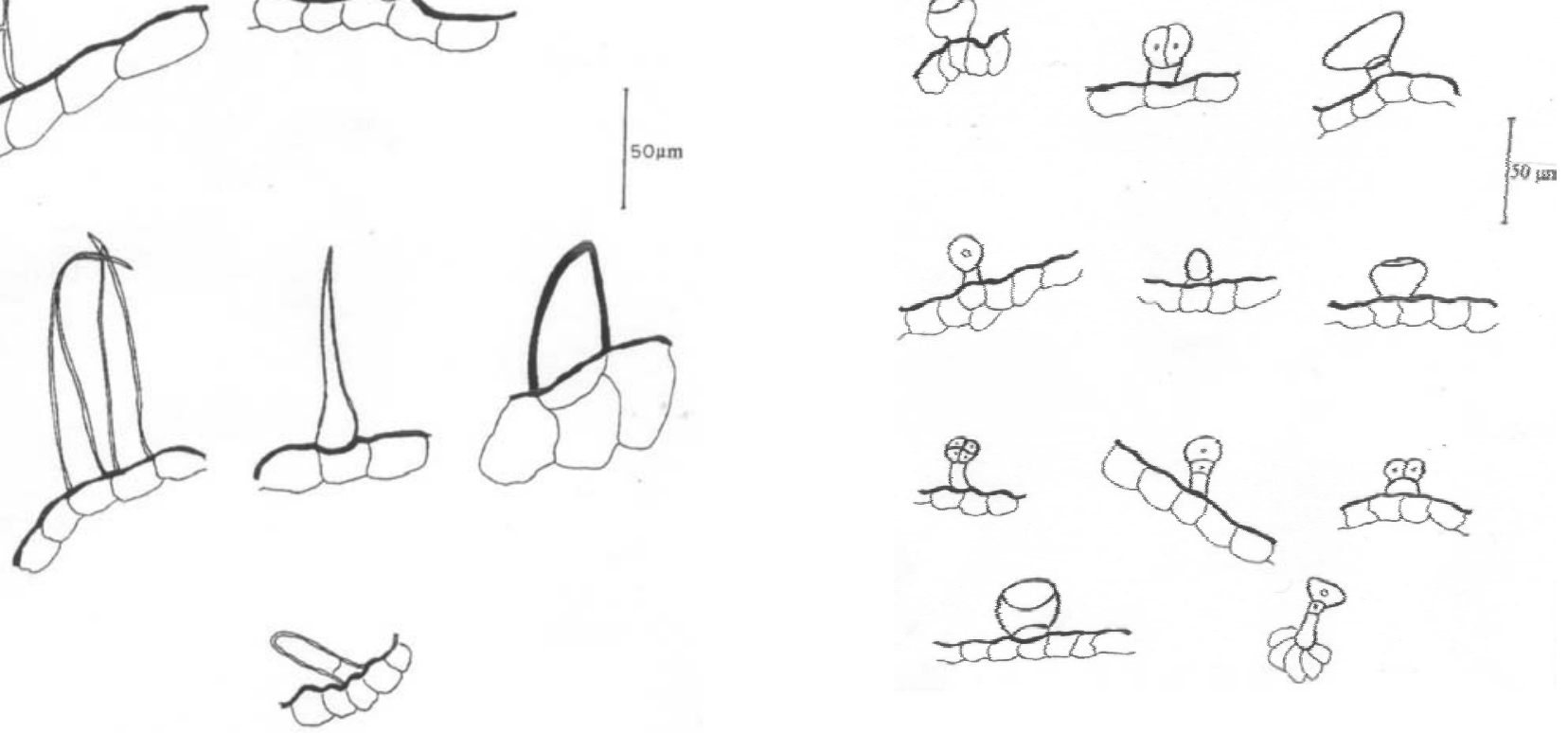

Figura 3. Desenho esquemático dos tricomas tectores (I) e glandulares (J) do caule jovem de Lippia alba
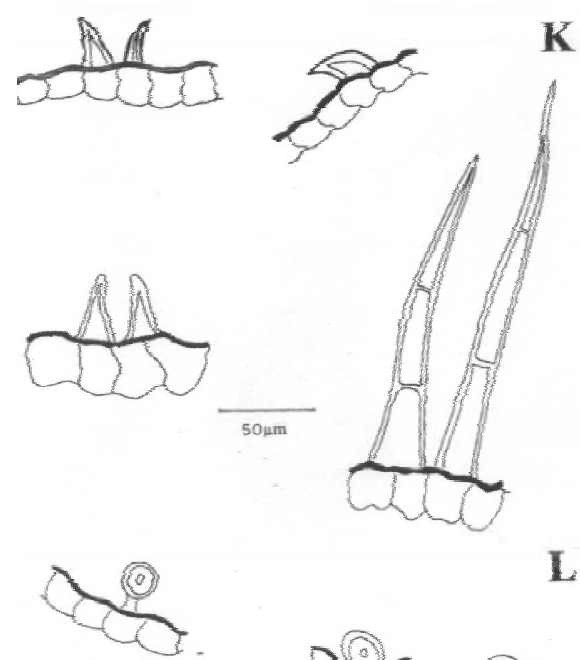

$\mathbf{L}$
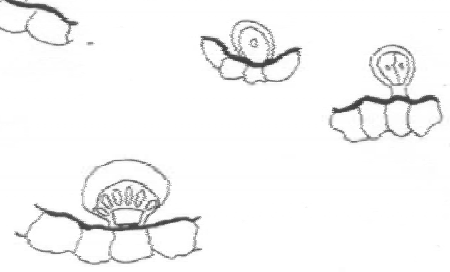

Figura 4. Desenho esquemático dos tricomas tectores (K) e glandulares (L) do caule jovem de Melissa officinalis 


\section{Material e Métodos}

Os caules destinados ao estudo microscópico foram coletados de plantas de um ano de idade cultivadas no bairro de Jacarepaguá (Colônia Juliano Moreira, FarManguinhos, Fiocruz, RJ) e as respectivas exsicatas depositadas no Jardim Botânico do Rio de Janeiro com os códigos RB 377575 (L. alba) e RB 340344 ( $M$. officinalis). Empregaram-se fragmentos de caules jovens e adultos com 0,5 a 1,0cm de diâmetro. Os cortes foram efetuados em micrótomo manual do tipo Ranvier, com o auxílio de navalha histológica; diafanizados em sol. de hipoclorito de sódio (10\%) e corados com hematoxilina ou safranina (coloração simples) ${ }^{7}$ e verde iodo/vermelho do congo, segundo a técnica de dupla coloração .

As fotomicrografias foram obtidas respectivamente com o equipamento Exakta e o fotomicroscópio Jena.

\section{Referências Bibliográficas}

${ }^{1}$ da Silva, R. A. Pharmacopeia dos Estados Unidos do Brasil, Companhia Editora Nacional Farmacopéia Brasileira, 1926; 503

${ }^{2}$ British Herbal Pharmacopoeia- 2.impress. - The British Herbal Medicine Association, Bournemouth, UK. p.141, 1987.

${ }^{3}$ Who monographs on selected medicinal plants. World Health Organization, Geneva, v.2, p.180-187, 2002.

${ }^{4}$ Corrêa, C.B.V. Contribuição ao estudo de Lippia alba (Mill.) N. E. Br. ex Britt. \& Wilson - erva cidreira. Revista Brasileira de Farmácia,v.73, n.3, p.57-64, 1992.

${ }^{5}$ Ferreira, J.L.P.; Amaral, AF.C.; de Paula, AE.S.; Carvalho, E.S.; Simões, E.V.; Gilbert, B. Chemical and morphological standardization of Cymbopogon citratus (DC.) Stapf. Bolletino Chimico Farmaceutico, v.138, n.2, 1999.

${ }^{6}$ Matos, F.J.A. As ervas cidreiras do nordeste do Brasil - Estudo de três quimiotipos de Lippia alba (Mill.) N. E. Brown (Verbenaceae) Parte I - Farmacognosia. Revista Brasileira de Farmácia,v.77, n.2, p.65-67, 1996.

${ }^{7}$ Oliveira, F.; Saito, M.L. Práticas de Morfologia Vegetal. Rio de Janeiro (RJ): Livraria Atheneu editora, p.109110, 1991.

${ }^{8}$ Dop, P.; Gautié, A. Manuel de Technique Botanique. Histologie et Microbie Végétales. Deuxième edition, Paris: J. Lamarre éditeur, v.47, p.108-111, 1928.

\section{*Autor para correspondência}

Prof. Dr. José Luiz Pinto Ferreira

Laboratório de Química de Produtos Naturais, Far-Manguinhos - FIOCRUZ

Rua Sizenando Nabuco, 100 - Manguinhos

Rio de Janeiro (RJ) - Brasil - CEP 21041250

Email josepint@far.fiocruz.br 